\title{
The Realistic Representation, Inducing Factors and Governance Strategy of Family Corruption
}

\author{
Qiwen Tang ${ }^{1, *}$ \\ ${ }^{1}$ Department of Law and Politics, North China Electric Power University. Baoding, Hebei 071000, China \\ *Corresponding author. Email: 2097958485@qq.com
}

\begin{abstract}
Since the 18th national congress of the communist party of China (CPC), the CPC central committee with Xi Jinping at the core of leadership has launched an anti-graft campaign with an all-inclusive and zero-tolerance attitude. Among all the corrupt behaviors, "family corruption" has undoubtedly become a typical corrupt behavior, which has bad social influence, diverse forms and distinctive characteristics. Family corruption can be divided into three modes according to the characteristics of corruption behavior, namely, common bribery mode, power shadow mode and option investment mode. The factors leading to family corruption are various. We can make a systematic analysis from four aspects: organizational system, social supervision, officials and family ethics. Through the analysis of the factors that induce family corruption, we can actually determine the corresponding governance strategies: improve the system, strengthen supervision, update the concept, and cultivate political ethics.
\end{abstract}

Keywords: family corruption; realistic representation; inducing factors; governance strategy

\section{INTRODUCTION}

Since the 18th national congress of the communist party of China (CPC), the fight against corruption has achieved remarkable results. With the anti-corruption storm advancing, Zhou Yongkang, Ling Jihua, Su Rong, and other groups of "big tigers" fall, and family corruption cases are increasingly surfaced. As a special type of corruption, this kind of family corruption behavior is extremely bad and has caused widespread concern in the society. The website of the central commission for discipline inspection has done statistics on cases of discipline violations suspected of family corruption. The results showed that from February 13, 2015 on December 13 , the central discipline inspection commission released a total of 34 provincial above and disciplinary action, including 24 of the violations involving family members, relatives, belonging to the family of corruption and accounted for as high as $64 \%$.

Therefore, I choose to study the subject of "family corruption". On the one hand, I hope to enrich the theoretical research on family corruption, on the other hand, I hope to provide theoretical guidance for solving this kind of corruption, so as to improve the credibility of the party and the government and effectively safeguard the interests of the country and the people.

\section{THE REALISTIC REPRESENTATION OF FAMILY CORRUPTION}

\subsection{The behavior pattern of family corruption}

The so-called family corruption refers to the behavior that public officials and their family members cooperate closely with each other, and use public power and influence to infringe on the public interests of the society in order to seek family interests

The components of family corruption are general, but the behavior patterns of family corruption in real life are different, which can be roughly divided into three modes.

\subsubsection{Common bribery mode}

The common bribery mode shows that corrupt officials "fight side by side" with their family members, that is, after leading cadres make use of public power to obtain convenience for others, their spouses, children or other family members take bribes behind the scenes. For example, su rong, former secretary of CPC Jiangxi provincial party committee, acquiesced and supported his relatives to use their power to frequently intervene in the land transfer, project construction, bidding, accepting and demanding huge amounts of property. 


\subsubsection{Power shadow mode}

This "shadow" is mainly divided into two aspects: on the one hand is a shadow career, on the other hand is a shadow business. Shadowing official career means that an official promotes family members through the power in hand, seeking the convenience of official career for them and acting as the "shadow person" for their promotion. For example, wang zhaoyao, former deputy secretary of anhui provincial party committee, bought and sold government posts to create a power family. Shadow commerce is the use of public power or influence by officials to facilitate the business activities of spouses, children and other family members. This kind of family corruption is mainly manifested in the fact that leading cadres provide power protection and relationship accommodation for their family members to open companies and take on projects. For example, zhao shaolin, the former secretary general of the communist party of China's jiangsu provincial party committee, used his position to smooth relations and seek illegal benefits for his son's company.

\subsubsection{Option investment mode}

This corruption pattern is manifested as: leading cadres regard their power as a kind of capital, and seek convenience for others by using their public power or influence, not seeking immediate return, but only seeking to "take care" of their families in the future. This "forward" model of corruption extends the time-space link in the exchange of benefits, with officials often retired when they take bribes. As a result, the pattern is more circuitous and less susceptible to detection.

\subsection{The characteristics of family corruption}

In real life, although the manifestations of family corruption are different, most of them have distinct characteristics in common. First, they commit crimes together. The main body of family corruption is a community of interests linked by blood and marriage. They are like "grasshoppers on a rope". The interest correlation of "one prosperity, one loss" determines the "division of labor and cooperation" among members, and the joint implementation of corruption. Second, the amount of corruption is huge. The purpose of family corruption is to maximize the interests of the family. The demand for interests changes from individuals to a family. Third, corruption is cheap. In family corruption, there is a key person who holds public power. Family members have surrounded this key figure, channeling and commercializing public power in return for the benefits the family needs, with little other input. Fourth, the concealment is strong and the detection is difficult. Officials and their family members cover each other in the process of corruption and have a clear division of labor. Officials act as honest and honest officials in front of the stage while family members take bribes behind the scenes

\section{INCLUDING FACTORS OF FAMILY CORRUPTION}

\section{1. organizational system}

\subsubsection{The restriction system is not detailed enough}

When power meets profit, under the temptation of various interests, if the organization's restriction system is not detailed enough, the authority may lose its power and fall into the abyss of corruption. China's central commission for discipline inspection (CCDI) held 58 plenums and more than 110 laws, regulations and policies related to family corruption between 1979 and 2011, according to a report released by the research center on the theory of clean government under the central commission for discipline inspection (CCDI). However, although a lot of relevant laws and regulations have been promulgated, there are still some problems such as unrefined and rough institutional norms. For example, "spouses and children of leading cadres are not allowed to engage in business activities that may conflict with the public interest within their business jurisdiction". In view of this regulation, how to define the issue of "business jurisdiction" and "conflict of public interest" will be a big problem in the specific implementation process. Although we have the relevant legal provisions, the institutional cage has loopholes, even if we promulgate the number of cages, it will not help.

\subsubsection{The supervision mechanism is not in place}

Montesquieu once said, "all who have power are prone to abuse the power in their hands. This is an eternal experience. Those who have power will use it until the boundary." Power is naturally corrosive and expansionary. If power is separated from effective supervision, it will gradually corrode the power holders and even their relatives.

As early as 2003, China promulgated the regulations on party supervision (for trial implementation). However, the specific supervision boundaries and standards are still relatively vague, which actually causes the "tangible but not real" supervision. What's more, in the face of huge profit temptation, supervisors may also fall into the trap of corruption. Because the supervision mechanism is not perfect, the officials engaged in supervision may play the role of both "supervisor" and "corrupter", ultimately leading to corruption beyond control. 


\subsubsection{Weak implementation of laws}

Throughout these years, there are many legal systems in China to avoid the corruption of relatives, but most of them are only in writing. In the process of implementation, most of these laws have the problem of "nominally". For example, since the promulgation of "the crime of illegally profiting for relatives and friends" in China, the public has rarely seen the case of being punished for this crime. Coincidently, according to the law on civil servants, civil servants who are related by husband and wife, direct blood relatives, collateral blood relatives within three generations and close relatives by marriage are not allowed to hold positions in the same organ where both sides are directly subordinate to the same leader or where there is a direct leadership relationship between superior and subordinate. However, in the case of zhang zhihuai, former director of the bureau of land and resources of suzhou city, anhui province, and zhang dong, former director of the sub-bureau of economic and technological development zone of the bureau of land and resources of suzhou city, anhui province, who were suspected of taking bribes, the father and son were blatantly acting as the superior and subordinate relationship.

Laws have not been rooted and effectively implemented, and corruption has not been effectively curbed. As a result, the cage guarding power has become empty, and officials cannot be restrained. Even with hundreds of legal systems, it is hard to stop corruption.

\subsection{Social supervision}

The dictionary of the Chinese university of law -- volume of constitutional law explains citizens' political rights as follows: "citizens enjoy the right to participate in political life, manage the country and express their personal opinions and opinions in political life in accordance with the law[1]."As the subject of public administration, citizens have corresponding civil rights. At the same time, according to the principal-agent theory, there is also a certain principal-agent relationship between officials and citizens, so the actions of officials should be naturally supervised by citizens.

However, in our country, there exists the phenomenon that the citizen supervision function fails to play. First, citizens have a weak sense of rights and responsibilities. In the face of official corruption, individual citizens tend to put themselves in the perspective of "outsiders", with a mentality of "no matter what you do, no matter what you do". Secondly, China's reward and protection mechanism for citizen supervision is not perfect. In real life, citizens are "well aware" of corruption. However, since the reward mechanism for reporting is not perfect enough, and citizens' enthusiasm for participating in reporting is not high enough, they will not take the initiative to report more things than less things. At the same time, ordinary people still have the mentality of "fearing officials", afraid of reprisals afterwards, "dare not speak in anger".

\subsection{Officials themselves}

It is the value ladder advocated and practiced by Chinese sages to cultivate one's morality, run the country, and govern the world. The ancients knew that cultivating one's morality is the foundation of family harmony. And so it is. Taking a look at the family corruption cases in recent years, all the officials involved in the case have alienated their thoughts and distorted their behaviors. Officials themselves are not right, break the bottom line, it may lead to the whole family on the road of distortion. Take Bai Enpei, former deputy director of the environment and assets supervision and administration commission of the National People's Congress, for example. His wife, Zhang Huiqing, also played an ignominously prominent role in bai's ten years in power in yunnan, where he frequently took money from mining, land and property development projects. Bai Enpei later confessed, "ideal lost faith, spiritual pursuit has not broken through the bottom line, even touch the red line of the law[2]".If officials have a weak sense of personal integrity and a low ability to resist temptation, their integrity will often collapse under the temptation of the outside world. Once they have grasped the power, they are likely to use public power as a tool to grab interests for themselves and seek illegitimate resources for their families.

\subsection{Family ethics}

\subsubsection{Negative influence of family ethics}

Since ancient times, the traditional Chinese society has always been a society that values family ethics, attaches great importance to consanguinity and separation. In this kind of society, the family concept based on blood background is deeply rooted and even affects people's behavior. As Wang Huning said: "although blood relationship is no longer being the basis of social relationship, but in quite a number of village community of family, kinship network still not break through, the combination of geographical and kinship still exists, the basic structure of the village family or clear, they still have considerable role in social regulation[3]".Under this family ethic, if one member of the family becomes an official, if he does not help other family members, he will be regarded as "ungrateful" and will be condemned by family members. In this way, an "illegal" morality is immaterial to officials, who tend to mix public domain with private domain when dealing with interest relations, or even put family interests above public interests.

\subsection{2. the influence of bad family style}

On October 16, 2015, the central commission for discipline inspection of the communist party of China (CPC) first put forward the term "family style is corrupt" in its notice on 
zhou benshun's "double opening". The circular put forward zhou benshun family corrupt, conniving at spouse and children, for their relatives to seek interests in business activities[4].

In ordinary families, parents who indulge their children or are lax in their discipline are likely to cause trouble outside, let alone the families of leading cadres. In an official's family, if the family style is bad and the discipline is not strict, it will incur bad consequences, which not only harm oneself, but also will harm the party and the country.

\section{GOVERNANCE STRATEGY OF FAMILY CORRUPTION}

\subsection{Improve the system to reduce the breeding space of family corruption}

Xi Jinping pointed out that "there should be a list of powers. What power can be used, what power can't be used, what is public power and what is private power should be separated from each other." the system is the best standard for distinguishing public and private areas[5].

\subsubsection{Define and refine existing constraint system}

First of all, we need to review all the past systems for restricting public power, and identify those that have been tested in practice and are effective and easy to implement. For these systems, once established must ensure the implementation, the formation of rigid constraints. We should avoid the appearance of "armchair" and "nominal" system.

\subsubsection{Improve the supervision system}

We can consider the improvement of the supervision system from two aspects. On the one hand, it is necessary to implement the personal reporting system, that is, public officials must report to the organization immediately when they encounter relevant personal and public affairs in order to avoid the risk of corruption. This actually facilitates the organization to supervise leading cadres. While establishing the system of reporting personal matters immediately, we should also expand the scope of disclosure of personal matters in an appropriate way, build an information disclosure platform, and make the declaration contents public in a timely manner. On the other hand, we should be good at using big data, artificial intelligence and other modern scientific and technological means to build a supervision system and break down the supervision barriers between different departments and units.

\subsubsection{Increase punishment}

In the case of Zhang Zhihuai and Zhang Dong, who took bribes, father and son, knowing the law and breaking the law, openly played the relationship between superior and subordinate in a unit and took the opportunity to collect money. Why this kind of behavior? It is clear that our laws do not deter lawlessness. Imagine if the penalty for violating the law that "direct blood relationship shall not be performed in the same unit as the superior relationship" were increased to the death penalty. Would anyone dare to touch this red line? Of course, this is only a more extreme hypothesis, such sentencing is lack of scientific and reasonable. However, we have to admit that the legal punishment of corruption in our country is too small, which encourages the fluke mentality of corrupt officials to some extent. Once found, serious treatment, and resolutely handed over to the relevant judicial organs for investigation and handling, this is the attitude we should face corruption.

\subsection{Strengthen supervision, cut off the mysterious connection between public power and private rights}

\subsubsection{Play the role of citizen supervision}

"The eyes of the masses are clear." Therefore, procuratorial organs should broaden the channels of reporting, such as the adoption of online reporting or telephone reporting and other new ways; At the same time, the relevant authorities should also do a good job of confidentiality, implement anonymous reporting, protect the whistleblower's personal information. Citizens' right to "speak up" is fully guaranteed, while citizens are encouraged to "speak up".

At the same time, citizens should correct their attitudes, enhance their sense of ownership and have the courage to use legal means to fight against corruption.

\subsubsection{Play the role of mass media supervision}

In China, the role of mass media in anti-corruption is more passive and after-the-fact reporting, and lack of active and pre-supervision, which weakens the supervision of mass media on non-corrupt.

First, the government should be aware of the role of the mass media in clean construction. The government should actively expand and improve the channels and mechanisms for the mass media to participate in anti-corruption, give them the right to supervise properly, and provide necessary institutional and policy guarantees in the early and active stage of mass media intervention. Secondly, mass media should also form a reasonable and effective mode of anti-corruption intervention on the basis of abiding by laws and their own industry norms. We should take active 
measures to present the latest developments in the government's crackdown on corruption and issues of concern to the people. We should release information on corruption that should and must be made public, so as to guide public opinion.

\subsection{Renew the concept, carry forward the good family style construction}

The reason why we emphasize the construction of family style is that it is not only a matter of one family, but also closely related to party style, government style, social style and folk style. An ordinary family if the family style is not right, easy to cause many family problems; For officials in leading positions, bad family traditions often become the rope that leads them, their families and their families to corruption.

As a leading cadre, we should not only "discipline ourselves", but also pay constant attention to our own family style. At the same time, the organization should also be at all levels of officials of the family building unremitting. We will integrate family style construction into the cadre assessment system, strengthen internal and external supervision of the family style construction of leading cadres, criticize and educate leading cadres whose family style is corrupt, and even deal with party discipline and government discipline, so as to make the family style construction "mandatory". Secondly, the organization should also conduct honest education for leaders and their families, the organization of honest patriotic training classes, watching honest family documentary, so as to enhance the party discipline and state law awareness of officials and their families.

At present, we should earnestly draw on the essence of excellent traditional family traditions and red family traditions, promote the renewal and remodeling of social concepts, actively advocate and cultivate modern fine family traditions, and build more correct consensus on social values for in-depth governance of family corruption.

\subsection{Cultivate political ethics, education of public power "master" honest public}

The generation of family corruption depends on the key figures in the family, that is, the leading cadres who hold public power. Therefore, if we want to further promote the governance of family corruption, we should seize the "key minority" of leading cadres and guide them to be honest and clean. As leading cadres, we should cast firm ideals and beliefs, temper and strengthen party spirit, and stand the test of interests. We should strengthen our sense of purpose and adhere to the principle of serving the people wholeheartedly and being responsible to the people. "We must have a correct view of power, position and interests, and bear in mind that the party and the people give us power[6]."And the leading cadre's "political man" to extend to the social and family identity, "to a noble moral sentiment and healthy life, strict with relatives of the children, a good family, should educate them establishing law-abiding, hard work and plain living, own good ideas, understanding that a cynical, graft are immoral things, and to do model for the whole society[7]."

\section{CONCLUSION:}

To sum up, family corruption has various forms and complicated influencing factors. This paper provides several representative inducing factors and governance strategies, providing ideas for solving family corruption. However, each family type of corruption has its own unique characteristics, we still need to be a case-by-case analysis.

\section{REFERENCES}

[1] Xu chongde, wu guang et al. Chinese dictionary of law - volume of constitutional law [M]. Beijing: xinhua press, 1984:277.

[2] Central commission for discipline inspection propaganda department, CCTV. Always on the road [M]. Beijing: China founder press, 2016.

[3] Wang huning. Village family culture in China: status and prospect $[\mathrm{J}]$. Academic quarterly of Shanghai academy of social sciences, 1991 (1): 106-114.

[4] Wang shaowei. A bad family wind blows.

[5] Commission for discipline inspection of the CPC central committee, literature research office of the CPC central committee. Excerpt from xi jinping's discussion on strict party discipline and rules [M]. Beijing: central document publishing house, China founder publishing house, 2015.

[6] Journal of zhejiang university (social science edition), 2013 (01): 5-13.

[7] Xi jinping on the governance of China: volume 2 [M]. Beijing: foreign languages press, 2017. 